\title{
The presence of Mycoplasma bovis in colostrum
}

\author{
Linde Gille ${ }^{1,6^{*}}$, Julien Evrard ${ }^{2}$, Jozefien Callens ${ }^{3}$, Karlien Supré ${ }^{4,7}$, Fabien Grégoire ${ }^{2}$, Filip Boyen ${ }^{5}$, \\ Freddy Haesebrouck ${ }^{5}$, Piet Deprez ${ }^{1}$ and Bart Pardon ${ }^{1 *}$
}

\begin{abstract}
In herds with Mycoplasma bovis circulation, colostrum is often considered infectious. However, in contrast to milk, the presence of M. bovis in colostrum was not previously evidenced. In this survey, the presence of M. bovis DNA was determined with real-time PCR in 368 colostrum samples from 17 herds, recently infected with M. bovis. Only $1.9 \%$ of the samples tested positive, with 13 herds having no positive samples and an overall within-herd prevalence of 3.2\% (SD: 4.9\%; Range: $0-30.0 \%$ ). These results show that in infected herds M. bovis DNA can be retrieved in colostrum. To what extend colostrum is infectious remains to be determined.
\end{abstract}

\section{Introduction, methods and results}

Mycoplasma bovis strongly contributes to economically important diseases like mastitis and pneumonia and heavily affects animal welfare and antimicrobial use in modern dairy farming [1]. Prevalence seems to be rising and increasing antimicrobial resistance has been reported as well $[2,3]$.

Between animals, the major ways of $M$. bovis transmission are direct nose to nose contact and aerosol spread [1] and consumption or contact with infected milk [4]. Introduction into a herd generally happens through purchase of replacement animals [5]. However, several other, currently under documented, ways of $M$. bovis introduction might exist. Troubling recent illustrations are the introduction of M. bovis in two Finnish herds by use of contaminated artificial insemination semen [6], and the first detection of M. bovis in New Zealand in July 2017 $[7,8]$. In the latter outbreak, import of embryos, feed, fomites, semen and other animal species were investigated as sources of this introduction, since no live cattle were imported since 2013, but to date the source remains

\footnotetext{
*Correspondence: linde.gille@uliege.be; bart.pardon@ugent.be

${ }^{1}$ Department of Large Animal Internal Medicine, Faculty of Veterinary Medicine, Ghent University, Merelbeke, Belgium

Full list of author information is available at the end of the article
}

unidentified [8]. In the current mindset of reducing antimicrobial use and improving animal health, it is imperative to prevent $M$. bovis introduction in farms and countries alike.

Colostrum was mentioned as a possible source of $M$. bovis in the past $[9,10]$, but to the author's knowledge, no studies on the prevalence of $M$. bovis in colostrum are currently available. Despite this lack of information, empirically designed $M$. bovis herd control programs often advocate the removal or (heat-) treatment of the herd's own colostrum as a precaution measure [4]. Withholding colostrum from neonatal calves is not an option, as they depend on colostrum to bridge the period from birth until their own immunity is fully functional [11]. Purchase of colostrum from other herds holds a risk for infectious diseases, especially paratuberculosis ( $\mathrm{Myco}$ bacterium avium subsp. paratuberculosis) [12] and will not provide the calf with herd-specific maternal immunity. Decontaminated colostrum (pasteurized or gamma irradiated) can be purchased, but this will result in a significant financial burden. Heat treatment lacks, especially in smaller farms, economical and practical feasibility due to the small amounts to be processed. Furthermore, heat treatment destroys the cytokine and cellular fraction of the colostrum, which seems to affect the calves' recovery after antigen exposure [13]. Knowledge on the prevalence

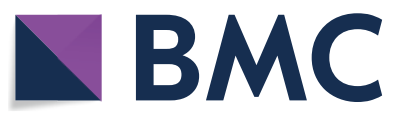

c) The Author(s) 2020. This article is licensed under a Creative Commons Attribution 4.0 International License, which permits use, sharing, adaptation, distribution and reproduction in any medium or format, as long as you give appropriate credit to the original author(s) and the source, provide a link to the Creative Commons licence, and indicate if changes were made. The images or other third party material in this article are included in the article's Creative Commons licence, unless indicated otherwise in a credit line to the material. If material is not included in the article's Creative Commons licence and your intended use is not permitted by statutory regulation or exceeds the permitted use, you will need to obtain permission directly from the copyright holder. To view a copy of this licence, visit http://creativeco mmons.org/licenses/by/4.0/. The Creative Commons Public Domain Dedication waiver (http://creativecommons.org/publicdomain/ zero/1.0/) applies to the data made available in this article, unless otherwise stated in a credit line to the data. 
of $M$. bovis in colostrum is essential to guide farmers in the choice of which preventive or control measures are preferentially taken. Therefore, the main objective of this study was to determine the presence of $M$. bovis DNA in colostrum samples from herds with a recent $M$. bovis infection.

A survey was conducted on seventeen farms throughout Belgium. Farms were conveniently selected by the local veterinarian and samples were collected throughout 2016 and 2017. The inclusion criteria were a recent (less than one month) M. bovis infection in the herd, documented by either positive culture or PCR, and the willingness of the farmer to participate. Farms could be either beef, dairy or dairy-mixed type. Four beef, five dairy and eight dairy-mixed farms participated (Table 1). Group A farms all had positive BAL or lung PCR samples in calves, without information on adults, whereas group B farms had confirmed $M$. bovis infection in both adult cattle and calves. Sample size calculations were preset on the available budget, which allowed the analysis of a total of 370 samples. Based on an average herd size of 80 lactating animals [3] and with an expected prevalence of $25 \%$ of the animals shedding, ten animals needed to be sampled in each herd to detect M. bovis with $95 \%$ confidence. A limit of twelve samples per herd was set on thirteen farms (Group A farms). Four farms with confirmed adult $M$. bovis cases were sampled for a longer time (six to twelve months) in an attempt to better characterize potential periods of shedding (Group B farms). Colostrum samples were collected by the farmer immediately post-partum after disinfection of the teats with gauze drenched in alcohol. A composite cow sample (pooled sample of all four quarters for each cow) was taken for each cow in a $15 \mathrm{~mL}$ Falcon $^{\mathrm{TM}}$ tube (Fisher Scientific, $\mathrm{NH}$, USA). Samples were stored on farm at $-20{ }^{\circ} \mathrm{C}$ until analysis. Farmers were informed on the most ideal sampling procedure and provided with the necessary material to perform this in a repeatable fashion. Because of the regional availability of two different laboratories where samples were sent to, two different real-time
PCR assays were used. In both laboratories, interpretation of PCR outcome was similar: samples were considered negative, borderline positive, or positive with a $\mathrm{Ct}$ value of $>40,37-40$, and $<37$, respectively. As the PCR protocols were used for colostrum, a non-standard medium, both protocols were verified for this matrix by use of spiked colostrum samples $\left(10^{8} \mathrm{CFU} / \mathrm{mL}\right)$. The samples of Group A farms were analyzed individually for the presence of $M$. bovis DNA by real-time PCR (VetMAX $^{\mathrm{TM}}$ M. bovis kit, ThermoFisher Scientific, MA, USA), targeting the $u v r C$ gene. Before analysis, samples were mixed with $\mathrm{PBS}$, centrifuged and the supernatants discarded. A mix of proteinase K/ATL buffer (Qiagen, Hilden, Germany) was added to the pellet before cell lysis. DNA was automatically extracted by use of the MagAttract 96 cador pathogen kit (Qiagen) and KingFisher ${ }^{\mathrm{TM}}$ Flex 96 Deep-Well Magnetic Particle Processor (Thermo Fisher Scientific ${ }^{\mathrm{TM}}$ ), according to the manufacturer. In Group B farms, pooled samples were examined using the real-time PCR Pathoproof ${ }^{\circledR}$ Complete 16-kit (Thermo Fischer Scientific ${ }^{\mathrm{TM}}$ ) according to the supplier's manual. Each pool consisted of five cow composite samples of cows belonging to the same herd. Samples of the $M$. bovis positive pools were analyzed individually the next day to find positive samples.

Data were entered in Excel 2016, and analyzed by SPSS version 25 (IBM, Armonk, New York, USA). In total, 368 colostrum samples from seventeen herds were analyzed (Table 1). M. bovis DNA was detected in $1.9 \%(7 / 368)$ of these samples, obtained from four different farms. Thirteen of the 17 sampled farms did not have any $M$. bovis positive colostrum samples. On the four farms that did have positive samples, on-farm/ within herd prevalence ranged between $2.8 \%(2 / 71)$ and $30 \%(3 / 10)$. The average within herd prevalence was $3.2 \%$ (standard deviation: $4.9 \%$; range: $0-30.0 \%$ ). Of the seven positive samples, five samples yielded a borderline positive $\mathrm{Ct}$ value $(>37$ and $<40)$. Only one farm $(2$ samples) was positive in group B. No pattern of shedding over time could be identified in group B farms, as very few samples were positive.

Table 1 Prevalence of Mycoplasma bovis in freshly calved cattle from recently infected herds.

\begin{tabular}{|c|c|c|c|c|c|c|c|c|c|c|c|c|c|c|c|c|c|}
\hline \multirow{2}{*}{$\begin{array}{l}\text { Study group } \\
\text { Herd number }\end{array}$} & \multicolumn{10}{|c|}{ Group A } & \multicolumn{7}{|c|}{ Group B } \\
\hline & 1 & 2 & 3 & 4 & 5 & 6 & 7 & 8 & 9 & 10 & 11 & 12 & 13 & 14 & 15 & 16 & 17 \\
\hline Type & $\mathrm{B}$ & B & $D$ & $\mathrm{D}$ & M & $M$ & M & B & M & $M$ & $M$ & $M$ & $M$ & $\mathrm{D}$ & $\mathrm{D}$ & $\mathrm{D}$ & B \\
\hline Total $n$ of cattle in herd & 161 & 139 & 74 & 103 & 209 & 121 & 216 & 152 & 205 & 245 & 316 & 433 & 282 & 587 & 363 & 311 & 241 \\
\hline$\%$ PCR Pos (p/nt) & $\begin{array}{l}0 \\
(0 / 6)\end{array}$ & $\begin{array}{l}0 \\
(0 / 11)\end{array}$ & $\begin{array}{l}0 \\
(0 / 8)\end{array}$ & $\begin{array}{l}0 \\
(0 / 3)\end{array}$ & $\begin{array}{l}0 \\
(0 / 12)\end{array}$ & $\begin{array}{l}0 \\
(0 / 5)\end{array}$ & $\begin{array}{l}30 \\
(3 / 10)\end{array}$ & $\begin{array}{l}10 \\
(1 / 10)\end{array}$ & $\begin{array}{l}0 \\
(0 / 10)\end{array}$ & $\begin{array}{l}0 \\
(0 / 11)\end{array}$ & $\begin{array}{l}0 \\
(0 / 4)\end{array}$ & $\begin{array}{l}11.1 \\
(1 / 9)\end{array}$ & $\begin{array}{l}0 \\
(0 / 11)\end{array}$ & $\begin{array}{l}0 \\
(0 / 63)\end{array}$ & $\begin{array}{l}2.8 \\
(2 / 71)\end{array}$ & $\begin{array}{l}0 \\
(0 / 74)\end{array}$ & $\begin{array}{l}0 \\
(0 / 50)\end{array}$ \\
\hline
\end{tabular}

$n=$ number; $\%$ PCR Pos = Percentage of positive samples; $\mathrm{p} / \mathrm{nt}=$ absolute number of samples positive over number of animals tested; Types: $\mathrm{B}=\mathrm{Beef}$ farm; $\mathrm{D}=$ Dairy farm, $M=$ Mixed farm. 


\section{Discussion}

This study aimed at determining the prevalence of $M$. bovis in colostrum. The study faces important limitations as we used the current, commercially available PCRs, originally manufactured for milk on colostrum samples. Diagnostic accuracy of these tests for colostrum is undocumented. We performed a limited validation to assure that positive samples are detected by spiking colostrum samples with $M$. bovis. Also, in the B group pooling of colostrum could have had an impact on the detection limit, given the high $\mathrm{Ct}$ value of the few positives detected, possibly other positive samples were missed. Therefore, current prevalence estimate needs to be interpreted carefully. Because colostrum samples can only be collected at one time point (just after calving), the decision was made to have the sampling performed by the farmer. Unfortunately, not all farmers complied $100 \%$ with the protocol and did not send in the twelve samples required for each farm to achieve the desired level of precision. Several PCR positive samples had a high Ct value, indicating only a marginal amount of $M$. bovis DNA present in the sample (Table 2). High Ct values could indicate the presence of other Mycoplasma species [14], and very high $\mathrm{Ct}$ values may also indicate carryover of DNA between samples [15]. Even though all farmers were instructed to take milk samples as aseptically as possible through an on-site demonstration, it is possible the actual sampling was not done lege artis in every case.

Taking these limitations into account, using these PCRs, M. bovis DNA was only sporadically detected in colostrum. It is unclear whether the concentration of bacteria present in colostrum would suffice to infect calves, especially in the case of marginally positive samples. Furthermore, the presence of live bacteria was not verified in this study and should be investigated further.

The main finding of this study was that M. bovis DNA could be detected in colostrum in a small number of samples. In the herds where a longitudinal follow-up was done, only two positive samples were found on a total of 258 samples, while $M$. bovis was still circulating in the herd during the entire study (based on sampling of clinical cases on nasal swabs or milk). A variation of colostral shedding was seen between the tested herds in this study, which could indicate differences in excretion of M. bovis. Hypothetically, this could be based on the time of introduction of M. bovis in the herd, where recently infected herds would have a higher level of shedding, concurrent with the rapid spread of a $M$. bovis strain through a seronegative population [16]. However, herd 17 was experiencing a large outbreak of $M$. bovis related disease in adult cattle at the time of sampling, after a primary introduction into the herd 1 month earlier, without any detectable shedding of $M$. bovis in the colostrum tested. Colostral shedding of $M$. bovis might also be linked to the disease form that $M$. bovis shows on a certain farm. One could suppose that farms suffering from $M$. bovis mastitis will have more shedding in milk. Given that case selection in group A was based on M. bovis positive tests in calves, this could have affected the isolation rate. However, group B farms were all selected based on M. bovis positive tests in adults. Overall, the within herd prevalence of $M$. bovis DNA in colostrum was very low, with the exception of one herd where $30 \%$ was tested positive. This might point to the fact that some individual herds are more affected, depending on the timing of infection of periparturient cows. Alternatively, it might be the consequence of false positive PCR results due to sample contamination or the presence of other Mycoplasma species $[14,15]$.

In conclusion, correct interpretation of the present results is crucial. M. bovis DNA is present in colostrum samples, albeit at low frequency. The DNA presence does not provide any information on the infectious risk of colostrum. Further work is needed to determine the risk of transmission trough colostrum and whether cows positive in colostrum have continued shedding in milk later in lactation.

Based on the findings of this study, farmers and veterinarians might be motivated to apply the precautionary principle and decontaminate colostrum or purchase colostrum (replacer). Discarding colostrum of cows suffering from $M$. bovis related pathologies is likely a good advice. We also recommend practitioners and farmers to avoid pooling of colostrum in infected farms. Pasteurization [9] and purchase of colostrum (replacers) are options, whereas freezing and subsequent thawing only reduces $M$. bovis concentration [17]. Acid treatment [18] of colostrum could be investigated as an alternative. Herd health advisors need to be aware that the investment cost for on-farm pasteurization and purchase of colostrum (replacers) might be high and that negative effects on herd immunity might be the consequence. Therefore,

Table 2 Ct-values of positive samples after real-time PCR and their interpretation.

\begin{tabular}{|c|c|c|c|c|c|c|c|}
\hline Source herd & Herd 7 & & & Herd 8 & Herd 12 & Herd 15 & \\
\hline Ct value & 37.14 & 38.87 & 38.2 & 38.36 & 29.14 & 34.3 & 39.8 \\
\hline Interpretation & Borderline & Borderline & Borderline & Borderline & Positive & Positive & Borderline \\
\hline
\end{tabular}


these measures are potentially not in economic equilibrium with the transmission risk via colostrum.

\section{Acknowledgements}

The authors wish to thank the lab technicians and all participating farmers and practitioners for their kind cooperation.

\section{Authors' contributions}

$L G, J C, J E, K S, F G, F B, F H, P D$ and BP assisted in study design, data analysis and manuscript preparation. JC, JE, KS and LG selected the farms. LG and JE gathered part of the samples and did data collection. FG and KS supervised the laboratory work. BP, PD, FB and FH supervised the scientific quality. All authors read and approved the final manuscript.

\section{Funding}

This research, and especially the laboratory analysis, was financed by the Flemish cattle monitoring project ("Veepeiler Rund"), headed by the Flemish Animal Health Service (DGZ-Vlaanderen) and the Walloon cattle monitoring project ("GPS bovin") headed by the Regional Association for Animal Identification and Health (Wallonie/ARSIA).

\section{Availability of data and materials}

All data on positive samples is available in the main manuscript. The full data set on PCR is available on request.

\section{Ethics approval and consent to participate}

Consent was obtained from all clients to use the colostrum milked post partum for this study. Sampling was generally done by the client or the farm veterinarian, following established guidelines and adherent to the high standards of veterinary care

\section{Competing interests}

The authors declare that they have no competing interests.

\section{Author details}

1 Department of Large Animal Internal Medicine, Faculty of Veterinary Medicine, Ghent University, Merelbeke, Belgium. ${ }^{2}$ Regional Association for Animal Identification and Health (ARSIA), Ciney, Belgium. ${ }^{3}$ Animal Health Service Flanders (DGZ-Vlaanderen), Torhout, Belgium. ${ }^{4}$ Flanders Milk Control Centre (MCC-Vlaanderen), Lier, Belgium. ${ }^{5}$ Department of Pathology, Bacteriology and Avian Diseases, Faculty of Veterinary Medicine, Ghent University, Merelbeke, Belgium. ${ }^{6}$ Present Address: Clinical Department of Production Animals, Faculty of Veterinary Medicine, University of Liege, Liege, Belgium. ${ }^{7}$ Present Address: Zoetis SA, Zaventem, Belgium

Received: 18 November 2019 Accepted: 2 April 2020

Published online: 16 April 2020

\section{References}

1. Calcutt J, Lysnyansky I, Sachse K, Fox LK, Nicholas RAJ, Ayling RD (2018) Gap analysis of Mycoplasma bovis disease, diagnosis and control: an aid to identify future development requirements. Transbound Emerg Dis 65:91-109

2. Gautier-Bouchardon AV, Ferre S, Le Grand D, Paoli A, Gay E, Poumarat F (2014) Overall decrease in the susceptibility of Mycoplasma bovis to antimicrobials over the past 30 years in France. PLoS One 9:e87672
3. Gille L Callens J, Supré K, Boyen F, Haesebrouck F Van Driessche L, van Leenen K, Deprez P, Pardon B (2018) Use of a breeding bull and absence of a calving pen as risk factors for the presence of Mycoplasma bovis in dairy herds. J Dairy Sci 101:8284-8290

4. Maunsell FP, Woolums AR, Francoz D, Rosenbusch RF, Step DL, Wilson DJ, Janzen ED (2011) Mycoplasma bovis infections in cattle. J Vet Intern Med 25:772-783

5. Fox LK, Kirk JH, Britten A (2005) Mycoplasma mastitis: a review of transmission and control. J Vet Med B Infect Dis Vet Public Health 52:153-160

6. Haapala V, Pohjanvirta T, Vähänikkilä N, Halkilahti J, Simonen H, Pelkonen S, Soveri T, Simojoki H, Autio T (2018) Semen as a source of Mycoplasma bovis mastitis in dairy herds. Vet Microbiol 206:60-66

7. McDonald WL, Rawdon TG, Fitzmaurice J, Bolotovski I, Voges H, Humphrey S, Fernando K, Canagasebey Y, Thornton RN, McIntyre L (2009) Survey of bulk tank milk in New Zealand for Mycoplasma bovis, using species-specific nested PCR and culture. NZ Vet J 57:44-49

8. Ministry for Primary Industries (2017) Analysis of risk patterns for the introduction of Mycoplasma bovis into New Zealand. Wellington, p. 5-17

9. Godden S, McMartin S, Feirtag J, Stabel J, Bey R, Goyal S, Metzger L, Fetrow J, Wells S, Chester-Jones H (2006) Heat-treatment of bovine colostrum. II: effects of heating duration on pathogen viability and immunoglobulin G. J Dairy Sci 89:3476-3483

10. Maunsell F, Brown MB, Powe J, Ivey J, Woolard M, Love W, Simecka JW (2012) Oral inoculation of young dairy calves with Mycoplasma bovis results in colonization of tonsils, development of otitis media and local immunity. PLoS One 7:e44523

11. Godden S (2008) Colostrum management for dairy calves. Vet Clin North Am Food Anim Pract 24:19-39

12. Streeter RN, Hoffsis GF, Bech-Nielsen S, Shulaw WP, Rings DM (1995) Isolation of Mycobacterium paratuberculosis from colostrum and milk of subclinically infected cows. Am J Vet Res 56:1322-1324

13. Gelsinger SL, Heinrichs AJ (2017) Comparison of immune responses in calves fed heat-treated or unheated colostrum. J Dairy Sci 100:4090-4101

14. Wisselink HJ, Smid B, Plater J, Ridley A, Andersson AM, Aspán A, Pohjanvirta T, Vähänikkilä N, Larsen H, Høgberg J, Colin A, Tardy F (2019) A European interlaboratory trial to evaluate the performance of different PCR methods for Mycoplasma bovis diagnosis. BMC Vet Res 15:86

15. Klaas I, Mahmmod Y, Katholm J, Nielsen S, Enevoldsen C (2016) Potentials and challenges for diagnosis of contagious udder pathogens with realtime PCR tests from samples at milk recording. Proceedings of the World Buiatrics Congress, Dublin

16. Arcangioli MA, Duet A, Meyer G, Dernburg A, Bezille P, Poumarat F, Le Grand D (2008) The role of Mycoplasma bovis in bovine respiratory disease outbreaks in veal calf feedlots. Vet J 177:89-93

17. Gille L, Boyen F, Van Driessche L, Valgaeren B, Haesebrouck F, Deprez P, Pardon B (2018) Short communication: effect of freezer storage time and thawing method on the recovery of Mycoplasma bovis from bovine colostrum. J Dairy Sci 101:609-613

18. Parker AM, House JK, Hazelton MS, Bosward KL, Mohler VL, Maunsell FP, Sheehy PA (2016) Milk acidification to control the growth of Mycoplasma bovis and Salmonella Dublin in contaminated milk. J Dairy Sci 99:9875-9884

\section{Publisher's Note}

Springer Nature remains neutral with regard to jurisdictional claims in published maps and institutional affiliations. 